\title{
Radiotherapy in thoracic malignancies: the preface
}

Lung cancer remains the most common cause of cancer-related deaths worldwide. This malignancy severely affects the quality of life, is associated with huge social impact, and carries a heavy economic burden due to expensive systemic therapies and immense indirect costs of lost productivity. The past decade brought tremendous progress in the practical implementation of screening and early detection, accurate staging, and local and systemic therapies. Despite these developments, even in the most developed countries 5 -year survival estimates remain below $20 \%$.

Radiotherapy is one of the basic treatment modalities in lung cancer and is used across all histology types and stages. Technical developments of radiotherapy have further strengthened and redefined its place in the management of lung cancer. High precision intensity-modulated radiation therapy, volumetric modulated arc therapy, and stereotactic body radiation therapy (SBRT), coupled with management of tumor motion and on-board imaging, increased efficacy and markedly decreased treatment-related toxicity. Integration of modern radiotherapy with systemic therapies allowed for unprecedented improvement of outcomes. An example of this progress is the doubling of median survival from approximately 18 months in the early 2000s to over 36 months now in stage III non-small cell lung cancer (NSCLC) patients managed with definitive radiotherapy. Today, SBRT is increasingly used in the treatment of medically inoperable and fragile patients with stage I NSCLC and in oligometastatic disease. Fractionated radiotherapy combined with chemotherapy is a well-established strategy for inoperable stage III NSCLC, and palliative radiotherapy is used to alleviate symptoms of disseminated disease. Thoracic radiotherapy and prophylactic cranial irradiation remain components of routine management in small cell lung cancer (SCLC).

In this series of Translational Lung Cancer Research, a group of renowned world experts presents the comprehensive and timely review of state-of-the-art radiation therapy in lung cancer and other thoracic malignancies. Dr. Badra et al. discuss current controversies and ongoing clinical research on SBRT for stage I NSCLC. Dr. Van Houtte et al. address indications and debates on preoperative and postoperative radiotherapy of NSCLC—still a highly controversial aspects of lung cancer management. Dr. Glatzer et al. present a Swiss consensus statement on the role of surgery and radiotherapy in stage III N2 NSCLC - the entity posing a particular clinical dilemma. A few articles address optimal radiotherapy planning and delivery in NSCLC: dose and fractionation schedules, challenges and evolving concepts in defining the target volumes, and tumor motion management. The role of systemic therapies in combination with radiotherapy is gaining increasing importance in stage III NSCLC. This aspect is addressed in the reviews on the combinations of radiotherapy with chemotherapy, targeted agents, and immune checkpoint inhibitors. Two important reviews present recent developments and ongoing controversies on thoracic radiotherapy and prophylactic cranial irradiation in SCLC. The last topic presented in this series is the role of radiotherapy in rare thoracic malignancies: pleural mesothelioma and thymoma.

We hope that the readers of Translational Lung Cancer Research will find this special series useful for their everyday practice and as an inspiration for research efforts.

\section{Acknowledgments}

Funding: None.

\section{Footnote}

Provenance and Peer Review: This article was commissioned by the editorial office, Translational Lung Cancer Research for the series "Radiotherapy in thoracic malignancies". The article did not undergo external peer review.

Conflicts of Interest: Both authors have completed the ICMJE uniform disclosure form (available at http://dx.doi.org/10.21037/ tlcr-21-335). The series "Radiotherapy in thoracic malignancies" was commissioned by the editorial office without any funding or sponsorship. JJ and RD served as the unpaid Guest Editors of the series and JJ serves as an unpaid editorial board member of Translational Lung Cancer Research from Oct 2017 to Sep 2021. The authors have no other conflicts of interest to declare. 
Ethical Statement: The authors are accountable for all aspects of the work in ensuring that questions related to the accuracy or integrity of any part of the work are appropriately investigated and resolved.

Open Access Statement: This is an Open Access article distributed in accordance with the Creative Commons AttributionNonCommercial-NoDerivs 4.0 International License (CC BY-NC-ND 4.0), which permits the non-commercial replication and distribution of the article with the strict proviso that no changes or edits are made and the original work is properly cited (including links to both the formal publication through the relevant DOI and the license). See: https://creativecommons.org/licenses/by-nc$\mathrm{nd} / 4.0 \%$.

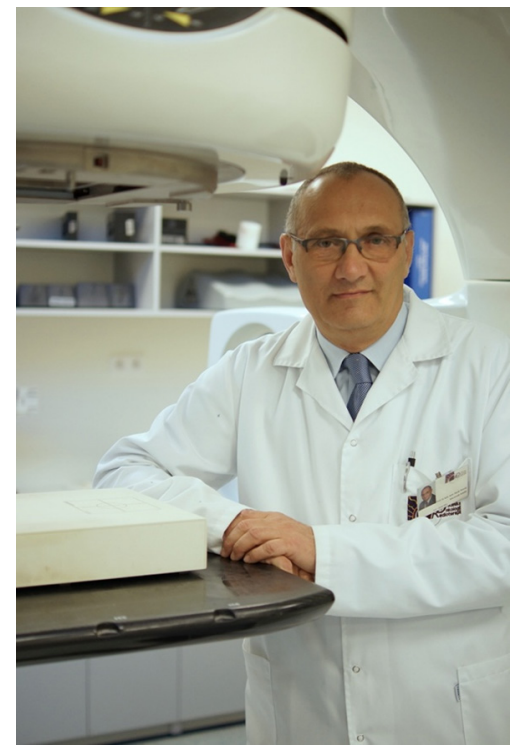

Jacek Jassem

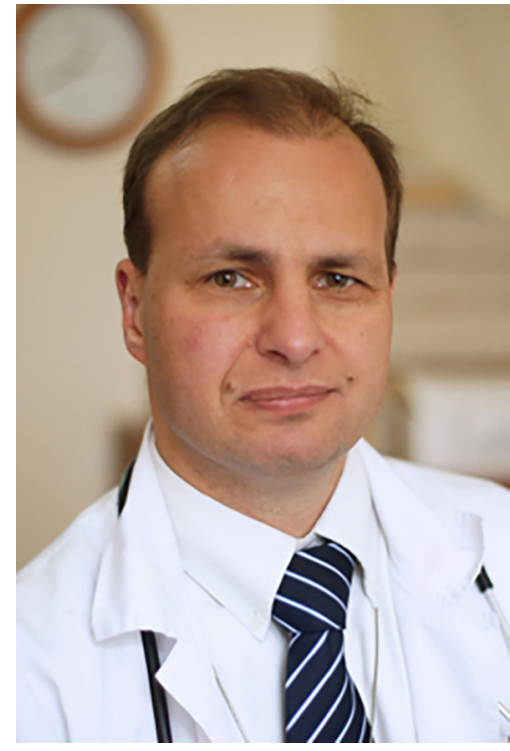

Rafał Dziadziuszko

Jacek Jassem, Rafał Dziadziuszko Department of Oncology and Radiotherapy, Medical University of Gdańsk, 17 Smoluchowskiego St., 80-215 Gdańsk, Poland. (Email:jjassem@gumed.edu.pl; rafald@gumed.edu.pl)

Submitted Apr 13, 2021. Accepted for publication Apr 25, 2021. doi: $10.21037 /$ tlcr-21-335 View this article at: http://dx.doi.org/10.21037/tlcr-21-335

Cite this article as: Jassem J, Dziadziuszko R. Radiotherapy in thoracic malignancies: the preface. Transl Lung Cancer Res 2021;10(4):1928-1929. doi: 10.21037/tlcr-21-335 